\title{
OS BAOBÁS DO FIM DO MUNDO: TRECHOS LÍRICOS DE UMA ETNOGRAFIA COM RELIGIÕES DE MATRIZ AFRICANA NO SUL DO RIO GRANDE DO SUL
}

The Baobás of the end of the world: lyrical excerpts from a african religion ethnography on the south region of Rio Grande do Sul

Los Baobás del fin del mundo: fragmentos líricos de una etnografía de religiones de origen africana en la parte sur de Rio Grande del Sur

$>$ Marília Kosby [Universidade Federal do Rio Grande do Sul, Brasil] ${ }^{*}$ José Darci Barros Gonçalves [Artista independente, Brasil] * *

RESUMO $\bigcirc$ ensaio reúne poemas de Marília Kosby e pinturas de José Darci, que compõem a primeira edição do livro Os Baobás do fim do mundo. Realizada em parceria entre a poeta e o pintor, a obra investiga possibilidades líricas através do encontro etnográfico realizado junto a terreiras na região de Pelotas, sul do Rio Grande do Sul. Os poemas e as imagens descrevem guias, caminhos e vertentes de uma força chamada axé, cuja arte de brotar, se desdobrar e espalhar é um saber gerado, transmitido e atualizado a partir da experiência da diáspora africana.

PALAVRAS-CHAVE poesia; pintura; encontro etnográfico; diáspora africana

ABSTRACT The present essay assembles poems written by Marilia Kosby and paintings from José Darci, which compose the first edition of the book Os Baobás do fim do mundo. Resulting from the partnership between poet and painter, the book investigates poetic possibilities through the ethnographic encounter with terreiras communities in the region of Pelotas, located on the southern region of Rio Grande do Sul state. The poems and images picture guias and pathways of a force called axé, with an ability to root and to spread itself that constitute a shared knowledge, informed by the experience of the African diaspora. KEYWORDS poetry; painting; ethnographic encounter; African diaspora 
KOSBY, Marília

DARCl, Zé. Os

Baobás no fim do

mundo, trechos

líricos de uma etnografia com religiões de matriz africana no sul do Rio Grande do Sul. Revista Poiésis, Niterói, v. 23, n. 39, p. 94-101, jan./jun. 2022.

[DOl: https://doi. org/ $10.22409 /$ poiesis.v23i39.52950]

Este documento é distribuído nos termos da licença Creative Commons Atribuição-Não-

Comercial 4.0 Internacional (CC-BYNC) (C) 2022 Marília Kosby, Zé Darci
RESUMEN El ensayo recoge poemas de Marília Kosby y pinturas de José Darci, que componen la primera edición del libro Os Baobás do fim do mundo. Realizada a través de la colaboración entre poeta y pintor, el trabajo investiga posibilidades poéticas mediante el encuentro etnográfico realizado junto a terreiras en la región de Pelotas, al sur del departamento de Rio Grande do Sul. Los poemas y imágenes describen guías y caminos de una fuerza llamada axé, portadora de una capacidad de germinar y de extenderse que constituye un saber generado y transmitido a través de la experiencia de la diáspora africana. PALABRAS CLAVE poesía; pintura; encuentro etnográfico; diáspora africana

* Marilia Kosby, poeta, é Doutora em Antropologia Social (UFRGS). E-mail: floorkosby@gmail.com. Orcid: https://orcid.org/0000-0003-1037-5490

* * José Darci Barros Gonçalves, artista plástico também conhecido como Zé Darci, desde 2009 integra o grupo de artistas Quilombos Urbanos 
A primeira edição do livro Os baobás do fim do mundo teve lançamento em 11 de novembro de 2011, na Bibliotheca Pública Pelotense, esgotando no mesmo ano, depois de realizar exposições de lançamento por diversos municípios do extremo sul do Brasil. Primeiro livro de poesia da poeta e antropóloga Marília Kosby, a obra foi uma parceria com o artista plástico José Darci Barros Gonçalves (Zé Darci), tendo sido publicada pela hoje extinta editora Novitas, de Vera Cruz/RS.

É bem possível ser "Os Baobás do Fim do Mundo" uma obra carente de definições mais precisas às vistas de quem por estas se interessar, é claro. Talvez seja sua publicação a expressão mesma desta busca por um lugar legítimo dentre as construções textuais que se erigem do encontro etnográfico; e que, simultaneamente imprimem neste a pretensão de ser uma experiência em parte apreensível pelos outros, os leitores.

O que se pode dizer a respeito dessa primeira compilação de textos em verso é que o material reunido foi escrito por uma antropóloga, e surgiu durante a fase de conclusão de seu mestrado acadêmico, cujo projeto de pesquisa se tratou da continuidade de um trabalho etnográfico realizado junto a terreiras na região de Pelotas, sul do Rio Grande do Sul.
Os três capítulos em que o livro se divide marcam a passagem de diferentes momentos da experiência etnográfica da autora, trazendo textos que expressam como foi sendo elaborado o conhecimento a respeito do modo de viver junto aos grupos com os quais estudava.

O primeiro capítulo, Etnodelírios, traz versos construídos em sonhos relacionados ao diário de campo, transcritos entre março e julho de 2008 , durante a realização do curso "Jogos, performances e simbolismos - etnografias afro-brasileiras", ministrado pelo professor Marcio Goldman, no Programa de Pós-Graduação em Antropologia Social do Museu Nacional, na Universidade Federal do Rio de Janeiro.

\section{Os textos apresentados no capítulo Do Banzo} foram escritos juntamente com sua dissertação de mestrado, intitulada "Se eu morrer hoje, amanhã eu melhoro: sobre afecção na etnografia dos processos de feitura da pessoa de religião no Batuque, em Pelotas/RS", trabalho defendido em abril de 2009 e orientado pela professora Flávia Rieth, no Programa de Pós-Graduação em Ciências Sociais da Universidade Federal de Pelotas.

Por fim, no capítulo Os Baobás do Fim do Mundo, tem-se os guias, os caminhos, as vertentes, de uma força chamada axé, cuja arte de brotar, se desdo- 
brar e espalhar, é um saber gerado, transmitido e atualizado a partir da experiência de pessoas negras trazidas como escravas da África para as Américas, e que, apesar disto, se constitui não apenas em um patrimônio étnico, mas numa significativa potência de dignidade e vitalidade de imensas minorias americanas. Os textos que compõem este último capítulo foram escritos entre 2009 e 2010, e se relacionam com a experiência de retorno ao campo, o que culminou na atualização de processos religiosos iniciáticos.

Os capítulos são ilustrados com reproduções fotográficas de pinturas do artista plástico Zé Darci (José Darci Barros Gonçalves), integrante do Grupo de Artistas Quilombos Urbanos, da região de Pelotas, e parceiro da autora em outros projetos artísticos.

Visando uma leitura mais compreensivel ao leitor que tem seu primeiro contato literário com o universo filosófico afro-brasileiro, esta obra consta de um glossário alfabeticamente organizado para as palavras sinalizadas em itálico.

Enfim, antes e além de tudo, este livro é uma forma de retorno ao pessoal "de religião", que encarregou sua autora de "levar a beleza de suas religiões para fora dos muros das terreiras". Beleza das "coisas que nos comovem, na medida em que, traduções míticas de nossa estrutura interior, lançam luz sobre nós mesmos ao mesmo tempo em que resolvem nossas contradições num acorde único".'

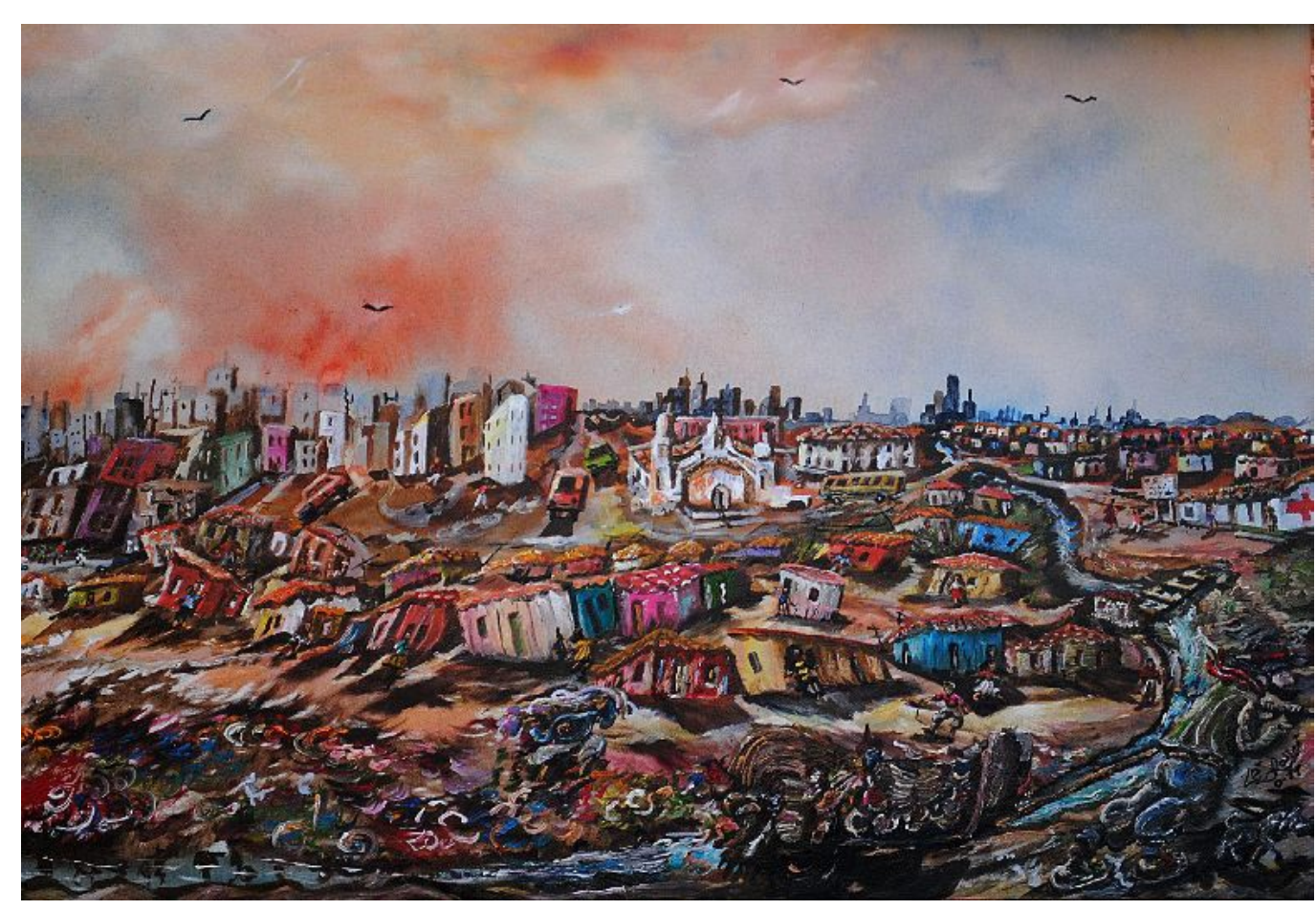

João Saudade, acrílica s/ tela. 
O OUTRO

Eu sou como você

porque tenho medo de você Medo

de servocê

e nunca mais encontrá-lo noutro lugar

fora daqui

Te perco tanto mais te sou

\section{ANTROPOLOGIAS}

Eu tenho as tuas palavras e uma dose quase nula de certeza

para ser capaz

de evitar as minhas

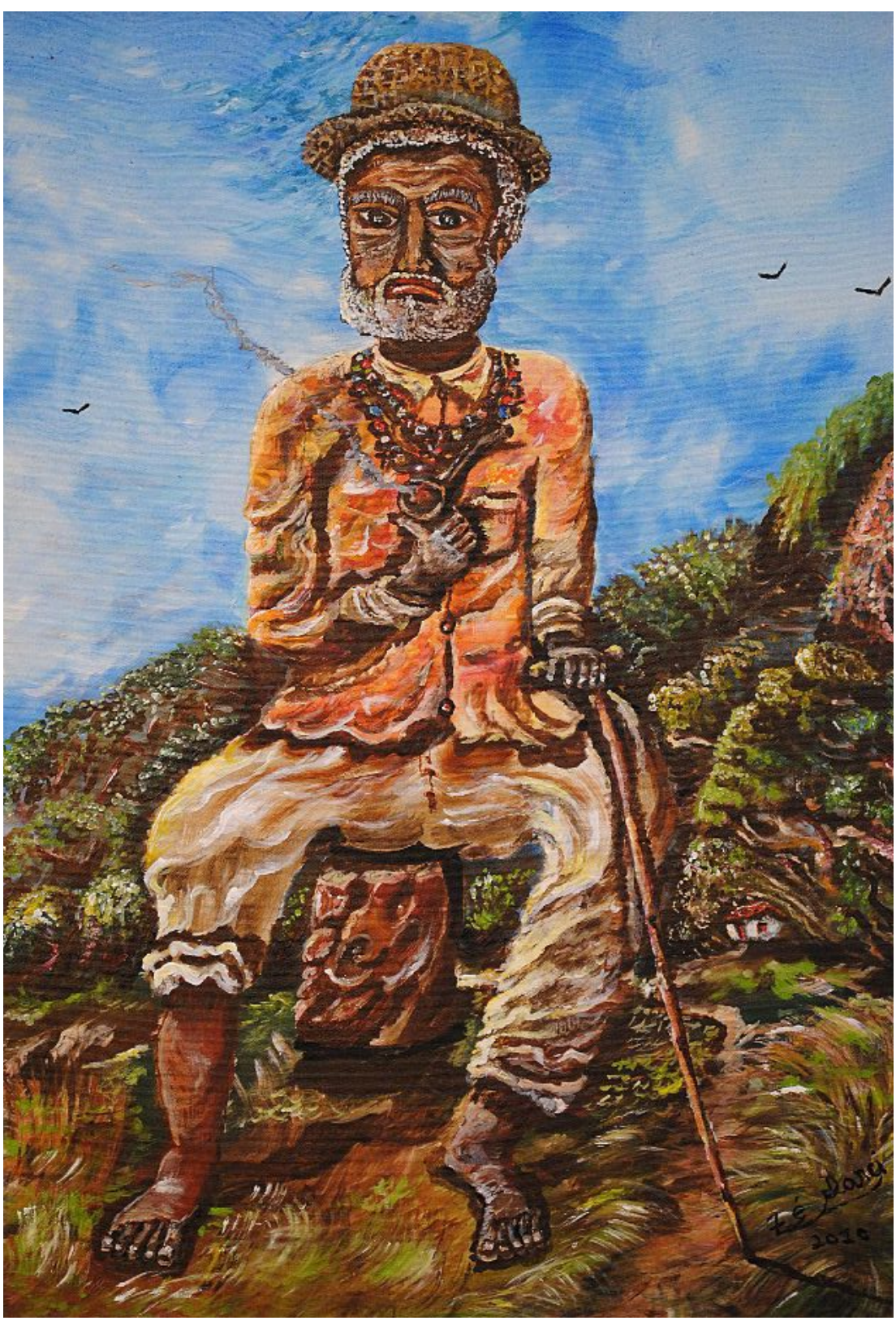

Pai Silvério, acrílica s/ tela. 
SACRIFÍCIO

Sacrificai o vosso corpo

em nome de um espaço que aguente vossos tempos de consciência e sanidade

Explicai vossos desejos

nos desenhos sujos de vossa pele intacta

Atravessai as horas, os metros cúbicos,

os anos bissextos

emaranhados em vossas palavras

sempre tão pequenas

compartimentos transbordantes

de uma vida que não sabe e nem conhece nada de irreal

Comparai o valor de vosso sangue

e percebei que o mundo que vos deram vossos planos

não abarca sonhos nem lampejos

Ele não contempla beleza e movimento

Orai ao vento

rogai ao vento

entregai ao vento

Ele que organize as contas

da desgraça que é ser

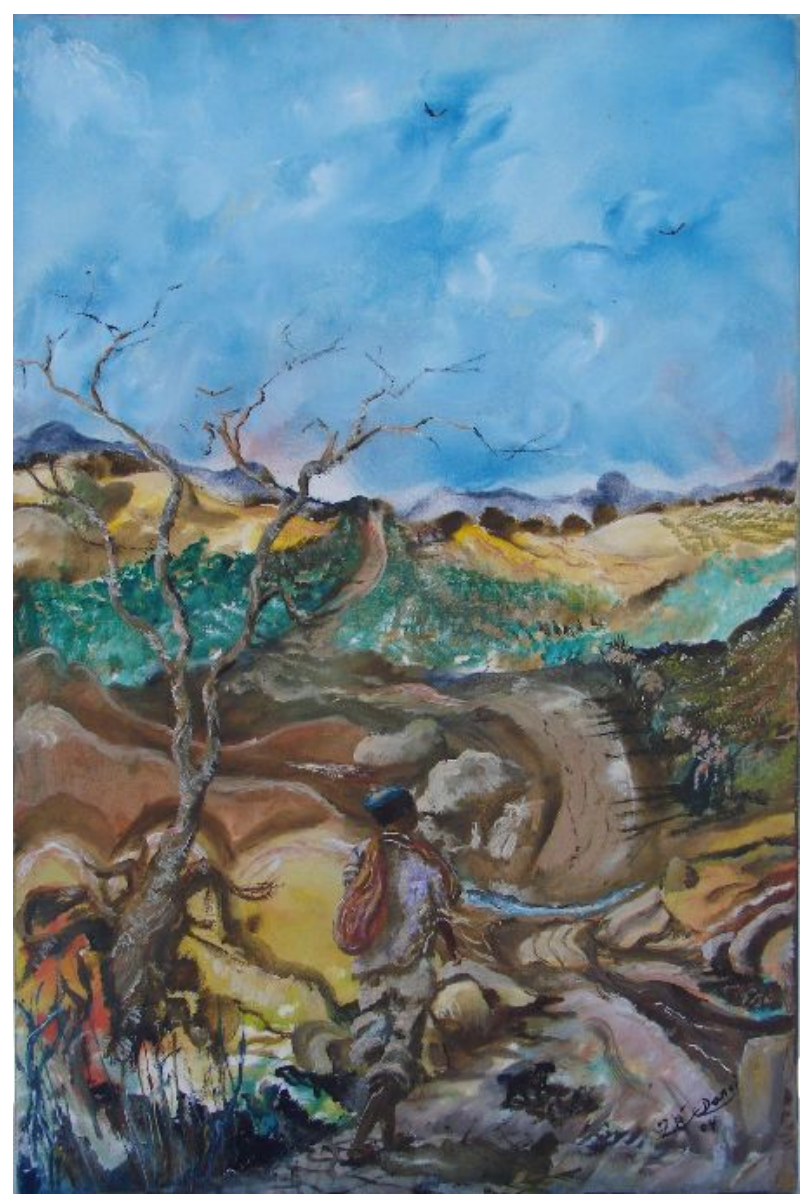

ao mesmo tempo

chão e bolha

céu e âncora 
OS BAOBÁS DO FIM DO MUNDO

Zimbábue

com "z", de beiço

O meu pai tem um pé no Xingu e outro no fogo A minha mãe, a boca de quem come flor

e gosta

Meus irmãos são só saudade

Os avós, um bicho grande

sangram entre o céu e eu

Enquanto os santos banqueteiam

agarradas às costas do mundo

as figueiras se eternizam

A SAIA DE MAMÃE

É tão linda a saia de mamãe

na beirinha da praia

É tão bonito ver o mar

todinho aos seus pés

Que ela lavre meu peito em segredos

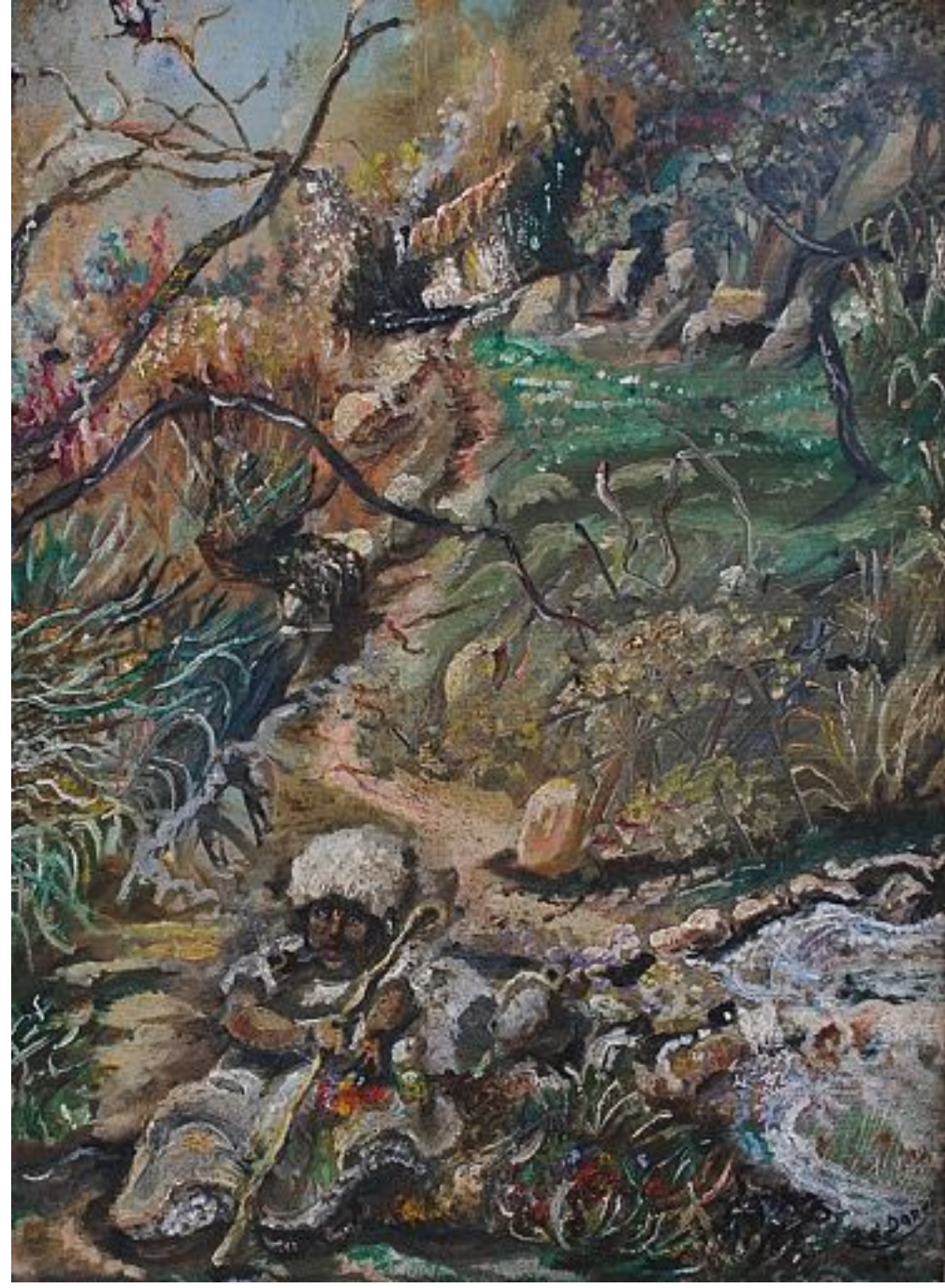

Vó preta, óleo s/ tela.

Que desfaça o feito em claridades

no meio dessa noite cega

NOTAS

é tudo o que eu posso pedir

Mamãe verte o mar com os olhos

ela embala as ondas no colo

1 LEIRIS, Michel. Espelho da tauromaquia. São Paulo: Cosac \& Naify, 2001. 